\title{
Editorial: Glass Structures \& Engineering, second issue: the Glass Age?!
}

\author{
J. Schneider · J. Belis • C. Louter • \\ J. H. Nielsen - M. Overend
}

Published online: 30 September 2016

(C) Springer International Publishing Switzerland 2016

\begin{abstract}
After the great success of the very first journal issue we proudly present to you the second issue of Glass structures \& engineering. We were pleasantly surprised by the overwhelming interest and very good reception of the journal by all of you. Once taking the printed version in our hands and going once more through the full content we were also very satisfied. We believe the efforts to start an international journal begin to pay off for our globalized community - at the same time this sets high standards for future issues.
\end{abstract}

\author{
J. Schneider $(\varangle)$ \\ Technical University of Darmstadt, Darmstadt, Germany \\ e-mail: schneider@ismd.tu-darmstadt.de \\ J. Belis \\ Ghent University, Ghent, Belgium \\ e-mail: Jan.Belis@UGent.be \\ J. Belis \\ Eindhoven University of Technology, Eindhoven, \\ The Netherlands \\ C. Louter \\ Delft University of Technology, Delft, The Netherlands \\ e-mail: Christian.Louter@TUDelft.nl \\ J. H. Nielsen \\ Technical University of Denmark, Lyngby, Denmark \\ e-mail: jhn@byg.dtu.dk \\ M. Overend \\ University of Cambridge, Cambridge, UK \\ e-mail:mo318@cam.ac.uk
}

Based on our stringent review process, seven papers were selected for the current issue summing up to more than 100 pages. Again, they show the variety of research activities and innovations in our field: from basic research on glass fragmentation and polymer interlayers to the development of new products with transparent polymers and laminates, numerical investigations on the structural behaviour and on stability problems of glass components, to construction and fullscale testing of connections and prototypes. Finally, questions on demolition and recycling of glass structures are addressed.

The knowledge we jointly develop and publish can also have a positive influence on the ongoing activities for standardization, e.g. of the design methodologies for glass structures with a new Eurocode for the whole of Europe and a new ASTM standard for the USA. Many of us are engaged in standard committees where we highly appreciate the latest input from research, practice and industry to be able to include innovation to the standards and not block it - how could this be better supported than through journal papers? In addition to the exchange of knowledge through the important international conferences in our field, like Engineered Transparency, Challenging Glass, GlassCon Global and Glass Performance Days, we all now have a new, strong channel for the dissemination of our work. After the positive echo to the first issue we are confident that Glass Structures \& Engineering is establishing itself as one of the focal points for innovation in structural glass engineering. 
Again, we want to encourage you for a continued support-by submitting and reviewing high quality papers and by citing them elsewhere, we all serve the whole structural glass community. Last but not least we want to sincerely thank our authors and reviewers for their efforts and you for reading and using the knowledge to foster innovation. Maybe we really are on our way to a new glass age..... 